\title{
Michel Dumas and Pierre-Marie Preux: Promoting Tropical Neurology Silently - The Gist of Their Contributions
}

\author{
Devender Bhalla ${ }^{\mathrm{a}-\mathrm{c}}$

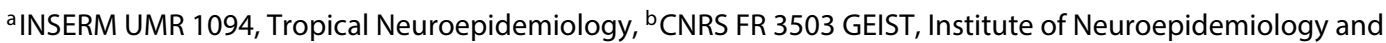 \\ Tropical Neurology, School of Medicine, University of Limoges and ${ }^{\complement}$ Centre Hospitalier Universitaire, Limoges, France
}

\section{Key Words}

Capacity-building $\cdot$ Dementia $\cdot$ Epilepsy $\cdot$ Health system . Neurology · Neglected tropical diseases · Research ·

Tropical countries

\begin{abstract}
This article presents the contribution by two senior French Neurologists over the past three decades in building, developing and promoting 'tropical neurology' in a number of neglected countries of Asia, Africa and Latin America. It talks about the 'human, dedicational and contributive value' of these two experts who do not come from an English-speaking world. It highlights meaningful changes that have been achieved in different tropical countries as a result of their direct contribution. This overview may likely be a cause for learning and motivation to others to really work in and for tropical countries, where a large proportion of global health burden is to be found.

๑) 2014 S. Karger AG, Basel
\end{abstract}

'To our shame, neglected diseases have not received the attention they deserve from the European Union for actions'. Such tell-tale statements in support of neglected diseases (ND) have appeared time and again, yet the little fundamental work on ND that has been done makes such statements and acknowledgments purely decorative.

Despite the restrictive and unsupportive environment around ND [1], the Institut d'épidémiologie neurologique et de neurologie tropicale of Limoges (France) has been actively working on a number of ND in a variety of 'less visible (neglected)' tropical countries. This institute was established in 1982 by Prof. Michel Dumas (fig. 1) and is currently run by Prof. Pierre-Marie Preux (fig. 2). Since then, the institute has been the only organization in Europe, and one of very few in the world, which has brought together two neglected themes: neurological disorders and tropical countries. By establishing this institute, Prof. Michel Dumas provided an apt platform for doing 'real' groundwork for addressing the neurological needs of those living in the tropical countries.

Although the term 'neglected' is frequently used in the literature, there has been nearly no attempt to precisely define what exactly is 'neglected'. The current list of ND includes infections only, while chronic conditions such as epilepsy, seizures, dementia, amyotrophic lateral sclerosis (ALS), stroke and multiple sclerosis (MS) have been subjected to similar neglect in developing/tropical countries. These chronic conditions also inflict a severe burden on the poorest regions and have a known association with several neglected infections that are endemic in these regions. Chronic conditions do not cause dramatic outbreaks but rather exact their toll over a longer period of

\section{KARGER}

E-Mail karger@karger.com

www.karger.com/ned
(C) 2014 S. Karger AG, Basel

0251-5350/14/0423-0139\$39.50/0
Dr. Devender Bhalla

Institut de Neurologie Tropicale (INSERM UMR 1094)

Faculté de Médecine, 2, rue du Dr Marcland

FR-87025 Limoges, Cedex (France)

E-Mail devender.bhalla@unilim.fr 
1

Fig. 1. Prof. Michel Dumas (permission obtained to use and publish photo).

Fig. 2. Prof. Pierre-Marie Preux (permission obtained to use and publish photo).

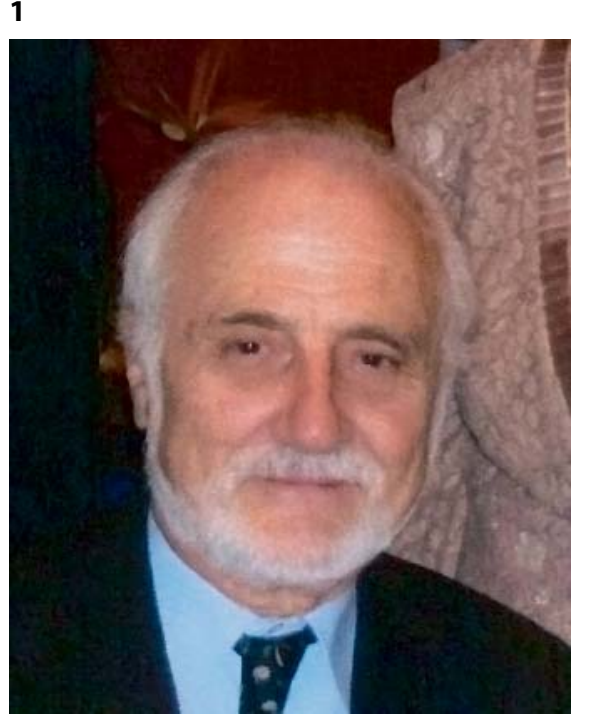

2

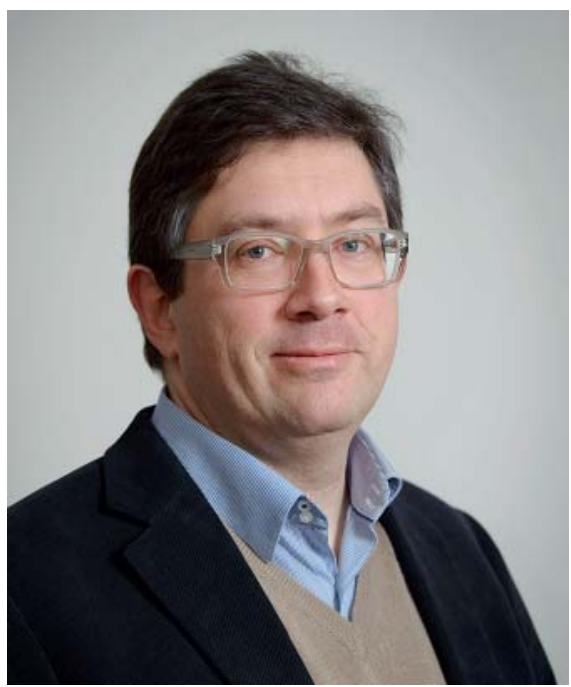

time, leading to crippling complications, severe disabilities and/or relatively slow deaths. For some of these chronic conditions, therapeutic and preventive solutions are available but are almost not utilized, which further adds to the irony of them being labelled as 'non-neglected'. With respect to some of these neglected (infectious and chronic) conditions, we discuss some aspects of the contributions made by Prof. Michel Dumas and Prof. Pierre-Marie Preux to the advancement of epidemiology and neurology, the development of scientific acumen and clinical capacity, and in turn the improvement of the state of public health in various tropical regions (table 1).

\section{Dementia}

Dementia is an important public health problem in tropical countries. They initiated and developed longterm research and action programs for dementia in several Central African countries, despite periodic bouts of civil unrest there [2-4]. They also identified a tool for determining the accurate age of dementia subjects - an extremely important issue in dementia research [5] - as well as certain psychosocial factors important in the survival of demented subjects [2].

\section{Human T-Lymphotropic Virus Type 1}

Human T-lymphotropic virus type 1 (HTLV-1) is a retrovirus implicated in a number of disorders, and they were one of the first groups to have conducted several surveys in West Africa to determine the seroprevalence and incidence of HTLV-1, and to have demonstrated a familial transmission and clustering of this viral disease in this subregion $[6,7]$. They had also demonstrated a correlation of HTLV-1 with spastic paraparesis, as well as with lifestyle, environmental and geographic factors, and with concomitant infections such as filariasis. For the first time, they had validated the lot quality assurance sampling method for field application to detect small clusters of infection.

\section{Central Nervous System Infections}

Their surveys and projects have helped to fill 'knowledge gaps' about several central nervous system infections in tropical Africa. Particularly, these central nervous system infections included onchocerciasis and cysticercosis [8]. Interest by other research agencies in sleeping sickness (SS) has long declined in favor of other popular infections. However, they conducted several research and action programs for SS in tropical Africa that particularly helped to determine: appropriate trypanocidal (mono and combination) therapies for second-stage SS; the regulatory role of several antibodies [9] and cytokines; and the development of validated models for carrying out immunopathological, neurohistological and therapeutic studies on SS [10]. The development of chronic experimental models for SS in animals with cerebral lesions and neurological disorders had been a matter of difficulty then [10]. 
Table 1. Summary of all relevant contributions

\begin{tabular}{|c|c|}
\hline Dementia & $\begin{array}{l}\text { Only source of knowledge about dementia from Central African countries } \\
\text { Tool for determining accurate age of dementia subjects identified } \\
\text { Psychosocial factors important in the survival of demented subjects identified }\end{array}$ \\
\hline Epilepsy & $\begin{array}{l}\text { Correlations with malaria and malnutrition } \\
\text { Screening of epilepsy questionnaire for tropical populations } \\
\text { Authoritative estimates of the prevalence of epilepsy in Asia and sub-Saharan Africa } \\
\text { 'Progression' from a prevalence survey to a provincial program on epilepsy in Cambodia, within merely } \\
3 \text { calendar years } \\
\text { Design and validation of epidemiological tools for many psychosocial parameters, which did not exist } \\
\text { before } \\
\text { A reliable estimate of the annual requirement of } 2 \text { antiepileptic drugs in Cambodia } \\
\text { Validation of reproductive causality of epilepsy } \\
\text { Estimate of the preventability of epilepsy, done for the first time in Asia } \\
\text { Recognition of activities on epilepsy in Asia 'as a model for the investigation of epilepsy in developing } \\
\text { countries' }\end{array}$ \\
\hline Capacity building & $\begin{array}{l}\text { Neurologists and neurorehabilitation specialists, where none existed } \\
\text { Epidemiologists, neuroepidemiologists and public health specialists, where none or few existed } \\
\text { Long-term training programs for general practitioners and medical students (many are going on) } \\
\text { Very recently: introduction of 'new' epilepsy service providers (i.e. primary health center staff) in Asia }\end{array}$ \\
\hline $\begin{array}{l}\text { Providing a } \\
\text { scientific platform } \\
\text { and international } \\
\text { visibility }\end{array}$ & $\begin{array}{l}\text { International award for principal investigator from Gabon (for the first time in Africa) } \\
\text { Appreciation of local tropical experts by the president of their country } \\
\text { As a priority, conducted/organized several international conferences in low-income locations, with } \\
\text { particular participation of tropical experts from Africa, Asia and Latin America }\end{array}$ \\
\hline
\end{tabular}

HTLV-1 = Human T-lymphotropic virus type 1 .

\section{Epilepsy}

Their research action programs have recently demonstrated an epileptogenic role of malaria in Mali [11] and Gabon [12]. For this, in 2009 the Bruce S. Schoenberg International Award in Neuroepidemiology went to the principal investigator from Gabon (Prof. Edgard Ngoungou). This was the first time that someone from tropical Africa became an awardee. He is an ex-student of Prof. PierreMarie Preux, and interestingly received a 'letter of appreciation' from the President of Gabon as well (read: recognition of tropical experts through organized research).

Their estimates of the prevalence of epilepsy in Asia and sub-Saharan Africa are considered authoritative and are widely used. Their Limoges epilepsy screening ques- tionnaire is also widely used in tropical countries and has helped to standardize data collection on epilepsy. They have recently demonstrated a greater benefit of using individual, rather than household, questionnaires for determining the burden of neurological disorders in low-income countries [13].

Their recent activities on epilepsy in Asia have culminated in numerous first-time results, for instance: (a) validated epidemiological tools for rating self-esteem, fear, social support, discrimination, coping strategies, patientderived quality of life, etc. [14]; (b) an estimate of the annual requirement of two antiepileptic drugs in an Asian country (i.e. Cambodia); and (c) the validation of reproductive causality in epilepsy and a precise estimate of the preventability of epilepsy [15]. Besides this they are among 
the first researchers who have shown in Asia that not all epileptic populations are stigmatized, although stigma is nearly always accorded to epilepsy 'by default' [15]. In addition, some years ago they also demonstrated a two-way correlation of epilepsy with malnutrition in Africa [16].

Recently, experts of a parent body on epilepsy have repeatedly recommended that the activities regarding epilepsy in Asia (particularly in Cambodia) be a 'model for investigation of epilepsy in developing countries'. Several activities in epilepsy research are proceeding in a neighboring country, Laos, where the two researchers were the first and only to determine the true burden of epilepsy as well as several other, particularly treatment-related, aspects of epilepsy $[17,18]$.

Although training of local staff is often recommended as a means of bridging manpower and, consequently, the treatment gap in epilepsy [19], little thought has been given to which staff should be trained, since not just doctors but also neurologists, psychiatrists, nurses, pharmacists and midwives are insufficient in number and are also inequitably distributed. Very recently they have been instrumental in identifying a 'new' service provider (i.e. primary health center staff) for providing trained epilepsy care at a primary care level. For many reasons, this strategy is extremely suitable, especially for rural populations [19]. Based on this strategy, a provincial program for epilepsy has very recently been started in two Asian countries [19]; this is a rare achievement, since there are not many countries where a formal provincial/national program for epilepsy has been, or is, running. Interestingly, in the case of Cambodia, it took merely 3 years to progress from conducting a first-ever prevalence survey to starting a formal provincial program for epilepsy. Also, for the first time, a new strategy named 'domestic health visiting' has been devised and is also being tested to reach epilepsy patient populations in a standard, organized, professional and regular manner in two Asian countries [19].

\section{Capacity Building}

This is one of their most important contributions toward improvement of the health care system of recipient countries. Apart from extensive teaching activities at various home institutions, they have raised a whole new generation of researchers, neurologists and epidemiologists in the last three decades, most of whom are working in their home countries. As an example, where no neurologists existed 15 years ago, today 7 neurologists and 1 neurorehabilitation specialist are available in Cambodia [20].
Besides this the two professors have also trained several provincial practitioners (primary health center staff and general practitioners) in several African and Asian countries; many of such training programs are currently going on as well [20].

\section{Miscellaneous}

In another valuable contribution, they were instrumental in conducting a three-country survey of mutiple sclerosis (MS) that came out with extremely novel findings on the risk and prevention of MS [21]. In particular, outdoor leisure activities, in addition to sun exposure, were for the first time found to be associated with reduced risk of MS, with evidence of a dose-response relationship. This survey had received much appreciation from the experts working in the field of MS.

Low-income countries are rarely chosen as priority locations for conducting advocacy events and professional and academic exchanges. As an example, a parent organization for epilepsy has conducted only 4 congresses in a low-income location since 1909 and none at a lowincome location in the last 10 years. Due to the professors' efforts, low-income locations have been chosen 'with priority' to conduct such events, like the ones in Cambodia, Vietnam and recently in Paris, France, in which experts from 16 low-income countries (Asia, Africa and Latin America) were specifically invited and given travel bursaries to be able to participate. Another such event is currently being organized in Varetz, France, and experts from several low-income countries have been specifically given travel bursaries. Such events are important for the advocacy, direct participation of public and private stakeholders, and motivation as well as encouragement of local expertise.

The professors have also been extremely active regarding ALS, having created a first-ever register in France one of the only three such efforts in Europe [22]. Their institute is also France's sole ALS expert center. They have been among the few research groups to have actively utilized geoepidemiological tools in ALS research to identify aggregate zones of ALS in France. They have provided one of the few sources of knowledge about ALS from Africa and have since long established an active consortium of African neurologists and researchers working on ALS, called TROPALS (Study of ALS under the Tropics; www.tropals.unilim.fr/). Several nutritional factors and environmental toxins have been identified that serve as risk, prognostic and diagnostic factors for ALS. 
Due to limitations of space, many of their contributions have not been discussed here in detail, for instance: (a) the facilitation of programs of professional and academic exchange [20]; (b) the prioritization of silent diseases and 'silent countries' (e.g. ALS in Africa, MS in Cuba and Martinique, countries like Mali, Martinique, Burundi, Cambodia, etc.); (c) their contribution in the development of 'early neurology' in Africa (in the 1960s); (d) the development of time-tested public-private part- nerships, which are often crucial for sustaining research action programs; and (e) treatment programs for epilepsy that continue to bring people out of the 'epilepsy shadow' in many African and Asian countries.

\section{Disclosure Statement}

No conflicts of interest to declare.

\section{References}

1 Vanderelst D, Speybroeck N: Quantifying the lack of scientific interest in neglected tropical diseases. PLoS Negl Trop Dis 2010;4:e576.

2 Guerchet M, Mouanga AM, M'Belesso P, Tabo A, Bandzouzi B, et al: Factors associated with dementia among elderly people living in two cities in Central Africa: the EDAC multicenter study. J Alzheimers Dis 2012;29:15-24.

-3 Guerchet M, M'Belesso P, Mouanga AM, Bandzouzi B, Tabo A, et al: Prevalence of dementia in elderly living in two cities of Central Africa: the EDAC survey. Dement Geriatr Cogn Disord 2010;30:261-268.

4 Paraiso MN, Guerchet M, Saizonou J, Cowppli-Bony P, Mouanga AM, et al: Prevalence of dementia among elderly people living in Cotonou, an urban area of Benin (West Africa). Neuroepidemiology 2011;36:245-251.

5 Paraïso MN, Houinato D, Guerchet M, Agueh V, Nubukpo P, et al: Validation of the use of historical events to estimate the age of subjects aged 65 years and over in Cotonou (Benin). Neuroepidemiology 2010;35:12-16.

6 Preux PM, Macharia W, Vernant JC, Denis F, Dumas M: HTLV-I-associated facial nerve palsy in Africans and people of African descent. Research Group in Tropical Neurology. Ann Neurol 1998;43:684-685.

7 Vallat JM, Dumas M, Grunitzky EK, Akani F, Diop G, et al: Lack of association between peripheral neuropathy and HTLV-I infection in west Africa: epidemiological, serological and nerve biopsy study. J Neurol Sci 1993;119: 141-145.

8 Druet-Cabanac M, Preux PM, Bouteille B, Bernet-Bernady P, Dunand J, et al: Onchocerciasis and epilepsy: a matched case-control study in the Central African Republic. Am J Epidemiol 1999;149:565-570.
9 Girard M, Ayed Z, Preux PM, Bouteille B, Preud'homme JL, et al: In vitro induction of nitric oxide synthase in astrocytes and microglia by Trypanosoma brucei brucei. Parasite Immunol 2000;22:7-12.

10 Keita M, Bouteille B, Enanga B, Vallat JM, Dumas M: Trypanosoma brucei brucei: a long-term model of human African trypanosomiasis in mice, meningo-encephalitis, astrocytosis, and neurological disorders. Exp Parasitol 1997;85:183-192.

11 Ngoungou EB, Dulac O, Poudiougou B, Druet-Cabanac M, Dicko A, et al: Epilepsy as a consequence of cerebral malaria in area in which malaria is endemic in Mali, West Africa. Epilepsia 2006;47:873-879.

-12 Ngoungou EB, Koko J, Druet-Cabanac M, Assengone-Zeh-Nguema Y, Launay MN, et al: Cerebral malaria and sequelar epilepsy: first matched case-control study in Gabon. Epilepsia 2006;47:2147-2153.

13 Quet F, Preux PM, Huerta M, Ramirez R, Abad T, et al: Determining the burden of neurological disorders in populations living in tropical areas: who would be questioned? Lessons from a Mexican rural community. Neuroepidemiology 2011;36:194203.

14 Bhalla D, Chea K, Chamroeun H, Vichea C, Huc P, et al: Comprehensive evaluation of the psychosocial parameters of epilepsy: a representative population-based study in Prey Veng (Cambodia). Epilepsia 2013;54:13421351.
15 Bhalla D, Chea K, Hun C, Vannareth M, Huc $\mathrm{P}$, et al: Population-based study of epilepsy in Cambodia associated factors, measures of impact, stigma, quality of life, knowledge-attitude-practice, and treatment gap. PLoS One 2012;7:e46296.

16 Crepin S, Houinato D, Nawana B, Avode GD, Preux PM, et al: Link between epilepsy and malnutrition in a rural area of Benin. Epilepsia 2007;48:1926-1933.

-17 Odermatt P, Ly S, Simmala C, Angerth T, Phongsamouth $\mathrm{V}$, et al: Availability and costs of antiepileptic drugs and quality of phenobarbital in Vientiane Municipality, Lao PDR. Neuroepidemiology 2007;28:169174.

18 Harimanana A, Chivorakul P, Souvong V, Preux PM, Barennes H: Is insufficient knowledge of epilepsy the reason for low levels of healthcare in the Lao PDR? BMC Health Serv Res 2013;13:41.

19 Bhalla D, Preux PM: Manpower gap: an important barrier against reduction of the treatment gap of epilepsy. Seizure 2013;22:586587.

20 Bhalla D, Samleng C, Gerard D, Oum S, Druet-Cabanac M, et al: Epilepsy in Asia: a Cambodian experience. Neuroepidemiology 2013;40:260-263.

21 Dalmay F, Bhalla D, Nicoletti A, CabreraGomez JA, Cabre P, et al: Multiple sclerosis and solar exposure before the age of 15 years: case-control study in Cuba, Martinique and Sicily. Mult Scler 2010;16:899908.

22 Marin B, Couratier P, Preux PM, Logroscino G: Can mortality data be used to estimate amyotrophic lateral sclerosis incidence? Neuroepidemiology 2011;36:29-38. 